\title{
The Mediterranean diet in a world context
}

\author{
Nikos Alexandratos* $†$ \\ Consultant to, and former Chief of, the Global Perspective Studies Unit, Food and Agriculture Organization of the \\ United Nations (FAO), 00100 Rome, Italy
}

\begin{abstract}
Objective: To put the debate on the Mediterranean diet in context by highlighting historical and prospective changes in the level and composition of food consumption in the world and key Mediterranean countries.

Design: Data from FAO's food balance sheets are used to illustrate historical evolution. Projections to 2030 are presented from FAO's recent and ongoing work on exploring world food and agriculture futures.

Setting: International.

Results and conclusions: Many developing countries are undergoing diet transitions bringing them closer to the diets prevalent in the richer countries, i.e. with more energy-dense foods. There follows an increase in the incidence of diet-related noncommunicable diseases, which are superimposed on the health problems related to undernutrition that still afflict them. In parallel, many low-income countries are making little progress towards raising food consumption levels necessary for good nutrition and food security. Wider adoption of food consumption patterns akin to those of the Mediterranean diet hold promise of contributing to mitigate adverse effects of such diet transitions. However, the evolution of food consumption in the Mediterranean countries themselves is not encouraging, as these countries have also followed the trend towards higher shares of energy-dense foods. Possible policy responses to these problems include measures to raise awareness of the benefits of healthier diets and/or to change relative food prices in favour of such diets (by taxing fattening foods) or, at the extreme, making individuals who follow 'bad' diets, and thus are prone to associated diseases, bear a higher part of the consequent costs borne by the public health systems (tax fat people).
\end{abstract}

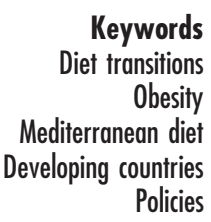

The debate on global issues of agriculture, food and nutrition has traditionally reflected perceptions of food scarcitiesactual, imminent or potential-under a perceived Malthusian race between food and population ${ }^{1}$. However, the long-term historical trends have been pointing in the opposite direction: at the global level, apparent food consumption ( $\mathrm{kcal} /$ person/day as a world average) has been getting more plentiful and varied, not scarcer, notwithstanding the hefty increases in world population ${ }^{2,3,8}$ (the term 'apparent' food consumption, often also called 'availability', refers to the

tThe views expressed are the author's, not necessarily those of FAO. ‡Apparent food consumption $=$ production + imports + beginning stocks - exports - non-food industrial uses - feed - seed - waste (post harvest to retail) - ending stocks. Post-retail and household waste or feeding to pets food designated for human consumption are, therefore, included in apparent food consumption and can be considerable in some countries ${ }^{4}$. All data on apparent food consumption used in this paper are from FAO's data bank FAOSTAT (http://faostat.fao.org/faostat/default.jsp?version= int\&hasbulk =1) except where indicated otherwise. The notation 1999/2001 indicates the three-year average 1999-2001. domestic disappearance for human consumption of food commodities at the retail level computed in FAO's food balance sheets (FBS) for each country $\ddagger$ ).

The trend towards increasing world averages notwithstanding, significant parts of the world's population (some 800 million people, mostly in Africa and Asia ${ }^{5}$ ) continue to have food consumption levels well below nutritional requirements. This reflects the persistence of poverty, lack of development, wars, etc. rather than global constraints to producing enough to meet the nutritional needs of everyone in the world. However, local constraints to increasing food production due to natural resource paucity and associated failures to develop agriculture are often important factors explaining the persistence of hunger in several countries which combine high demographic growth, significant dependence on local agriculture and few alternative avenues to sustained development, e.g. Niger. Localized Malthusian situations are not to be excluded even in a world with plentiful food supplies and more than sufficient production potential globally ${ }^{6}$. 
The rise in the world average food consumption in recent decades reflected primarily the gains made by many developing countries, with China dominating the scene. Many of these countries have been gradually attaining consumption levels and patterns approaching those prevalent in the industrialised world, in particular as regards changes in diets towards energy-dense ones high in fat, particularly saturated fat, sugar and salt and low in unrefined carbohydrates. In combination with lifestyle changes, largely associated with rapid urbanisation, a corresponding increase in diet-related chronic noncommunicable diseases (NCDs) has been observed. In many countries undergoing this transition, the obesityrelated NCDs appear when health problems related to undernutrition of significant parts of their populations are still widely prevalent ${ }^{7}$. The two problems coexist and present these countries with novel challenges and strains in their health systems.

The increases in per capita food consumption and the change of diets towards more livestock products are set to continue. While it is beneficent in many countries with still inadequate diets, these further changes will likely be accompanied in many cases by enhanced risks of increased incidence of diet-related NCDs. In the next section, we present projections of the possible evolution of world food consumption (levels and structure) to the year 2030 from recent ${ }^{8}$ and ongoing work in FAO.

\section{Evolution of food consumption in a diverse world: past, present, future}

Table 1 presents the historical data and projections to 2030. The massive improvement that occurred in the average food situation ( $\mathrm{kcal} /$ person/day) in the developing countries in the past three decades is evident in these data. It can be further appreciated by noting that in the early 1970s three-quarters of their population of 2.6 billion lived in countries with under $2200 \mathrm{kcal} /$ person/day. Both India and China, with a combined population of 1.37 billion in 1970, belonged to this class. The situation had changed dramatically by the end of the century: only $12 \%$ of their much larger population ( 4.7 billion) lived in such countries, while $50 \%$ of the population lived in countries with over $2700 \mathrm{kcal}$, up from only $4 \% 30$ years earlier. This general progress reflected principally the growth of apparent food consumption in some of the most populous developing countries, foremost among them China, but also Indonesia, Brazil, Mexico and, to a smaller extent, also Nigeria, India, Egypt, Iran and others.

Structural change in favour of energy-dense foods (livestock products, vegetable oils, sugars) is evident in the historical evolution. Only half a dozen developing countries (in South America but also pastoral Mongolia) had over $50 \mathrm{~kg}$ of meat per capita three decades ago, while the great bulk of the population $(75 \%$, including China and India) lived in countries with under $10 \mathrm{~kg}$. The proportions had changed dramatically by the end of the century, reflecting above all China's rapid growth, with the country approaching $50 \mathrm{~kg}$. Change would have been even more pronounced were it not for India, which has so far proved very resilient in resisting penetration of meat-eating habitsa phenomenon reflecting both persistent massive poverty and cultural/religious factors 9 . The gradual shift of more and more countries towards diets having structures exceeding recommended limits of 'bad' nutrients, highly correlated with the increase of the relative shares of livestock products, is also seen in the data provided in Table 2 (reproduced from Schmidhuber and Shetty, $2005^{10}$ ).

However, very pronounced differences in diet structures continue to exist among the individual countries. For example, food consumption of cereals is $220-250 \mathrm{~kg} /$ person/year in some countries (e.g. Egypt and Morocco, mostly wheat; or Burkina Faso, mostly millet and sorghum) and as low as $40 \mathrm{~kg} /$ person/year in others, e.g. Democratic Republic of Congo, Rwanda and Burundi, where roots, tubers and plantains predominate as sources of food energy.

According to the FAO projections (Table 1), the trend towards higher levels of per capita apparent consumption is set to continue, albeit at a slower pace than in the past, and so will the structural changes in favour of the energy-dense foods. However, the prospects for growth and further structural change differ greatly among countries and regions. Income growth plays a role in all cases, but its effects are mediated through complex interactions of a multitude of other factors (ecological, social, religious, demographic, urbanisation, health, policy, etc.) and, of course, the stage in the nutrition transition countries find themselves in at present determines how far they have still to go. Some countries have made the transition to more or less fairly high and stable consumption levels and livestock-rich diets (e.g. several industrialised countries) while others are at various stages in the transition. Still others have barely started the transition out of the traditional low levels and little diversified patterns, e.g. the roots/plantains-based diets in several lowincome countries in sub-Saharan Africa.

Given the prospects for overall development (not very promising for a number of developing countries*) and the persistence of the other factors determining diet structures, we can anticipate that countries will continue to have widely differing diet profiles in the future, though differences will be somewhat less pronounced than at present. In some countries, progress will not be sufficient to bring them even in 30 years time to levels of apparent per capita consumption compatible with reduction of undernutrition to tolerable levels ${ }^{8}$. The nutritional divide will be

\footnotetext{
* The latest World Bank assessment of prospects (p. 9) foresees that there will still be some 2 billion people in 2015 (compared with some 2.5 billion in 2002) living on less than $\$ 2$ a day in the developing countries, the bulk of them in South Asia and subSaharan Africa ${ }^{11}$.
} 
Table 1 Changes in the levels and commodity composition of apparent food consumption: world and major country groups

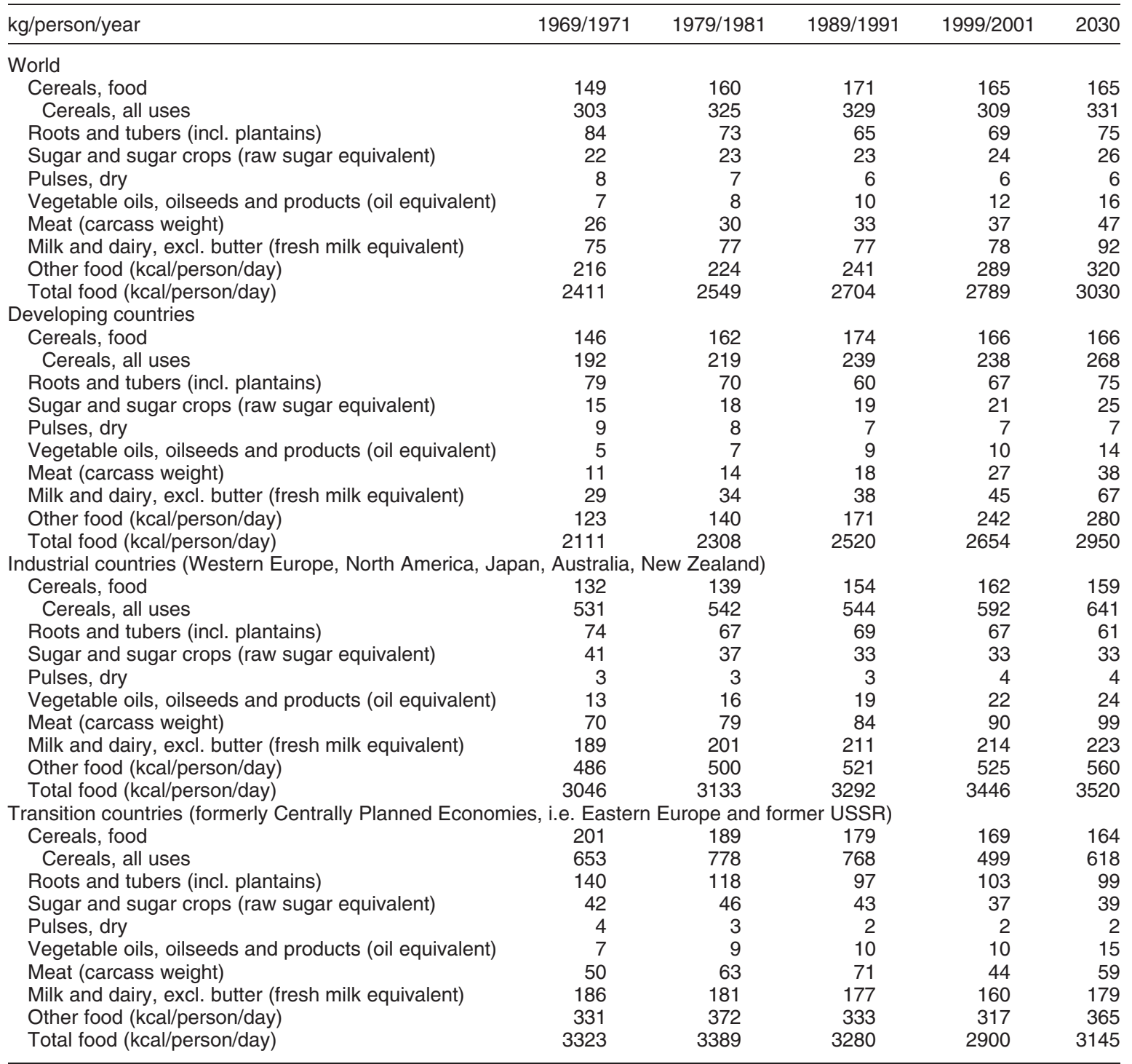

Note: Cereals food consumption includes the grain equivalent of beer consumption and of corn sweeteners.

Projections from Bruinsma, $2003^{8}$, Table 2.7 , with revisions from ongoing work by the author.

becoming increasingly evident within the group of the developing countries themselves rather than along the traditional dichotomy developed vs. developing. In the process, countries moving out of 'food poverty' proper will run the risk of falling into the trap of 'health poverty' as they transit towards food consumption levels and patterns associated with increases in the incidence of chronic NCDs, even before they have resolved problems of undernutrition of significant segments of their populations.

Promotion of the Mediterranean diet (MD) holds promise of mitigating the undesirable effects that accompany the diet transitions. We can gain some insights concerning the extent to which this may be a realistic prospect by examining how the MD has been faring in the Mediterranean region itself under the socio-economic transformations and related diet transitions of the last few decades.

\section{Evolution of diets in some Mediterranean countries}

To judge from the historical evolution of food consumption levels and structures, as depicted in the data of the national FBS, the experience does not augur well. The traditional MD seems to be in a moribund state in its very birthplace-allegedly Greece and within it Crete*. With the exception of the high consumption of olive oil and fresh fruits and vegetables, today's food consumption patterns in Greece (as national average) have moved away from those that were close to the MD prototype and were

\footnotetext{
*The term 'traditional Mediterranean diet' has a specific meaning. It reflects food patterns typical of some Mediterranean regions in the early 1960s, such as Crete, parts of the rest of Greece, and southern Italy ${ }^{12}$.
} 
Table 2 Apparent consumption of fats and cholesterol in excess of recommended levels

\begin{tabular}{lccccc}
\hline Limits & $1961 / 1963$ & $1969 / 1971$ & $1979 / 1981$ & $1989 / 1991$ & $1999 / 2001$ \\
\hline No. of countries & 158 & 158 & 158 & 158 & 178 \\
Total fat $>30 \%$ of total kcal & 28 & 31 & 43 & 54 & 61 \\
Saturated fatty acids $>10 \%$ & 47 & 49 & 50 & 55 & 62 \\
Cholesterol > 300 mg/day & 26 & 30 & 41 & 44 & 64 \\
\hline
\end{tabular}

Source: Reproduced from Schmidhuber and Shetty, $2005^{10}$ based on the FAO FBS. The larger number of countries in 1999/2001 than in earlier years reflects the new countries formed after the transformations of the former USSR and Eastern Europe.

Recommended levels are from Data Food Networking ${ }^{16}$.

prevalent as recently as the mid 1960s. Shifts that accompanied rapid urbanisation, growing incomes, technical change in the food industry, the rapid diffusion of fast-food outlets, and globalisation have led to greatly increased consumption of animal products, lipids other than olive oil (added lipids as well as those embodied in other foods) and sugar.

In the mid 1960s, Greece had a national average apparent food consumption yielding $2900 \mathrm{kcal} /$ person/day, with $29 \%$ coming from fats (13\% from olive oil) and 43\% from cereals. Meat consumption was a mere $33 \mathrm{~kg} /$ person/year and that of sugar $18 \mathrm{~kg}$ (raw sugar equivalent). Three and a half decades later, the $\mathrm{kcal} /$ person/day had risen to 3700 and fats from 92 to $152 \mathrm{~g}$ /day, accounting for $36 \%$ of total calories (12\% from olive oil). Meat consumption had risen to $88 \mathrm{~kg} /$ person/year and that of sugar to $32 \mathrm{~kg}$. No wonder that the incidence of obesity in Greece is among the highest in Europe and the world, with Crete itself holding place of pride in this transformation ${ }^{13,14}$. The evolution of diets in the other Mediterranean countries on the European side tells a similar story. Figure 1 shows these changes for Greece, Italy and Spain.

In the obesity data (percentage of adult population with body mass index $>30 \mathrm{~kg} / \mathrm{m}^{2}$ ) of both the International Obesity Task Force ${ }^{13}$ and the OECD ${ }^{15}$, Italy is at the bottom in the European obesity league, while Spain is in the middle position and Greece has the highest estimates. How can countries with fairly similar (though far from identical) diet levels/structures have so widely differing obesity rates? These divergences certainly raise the issue of reliability, comparability and mutual compatibility of the data on both apparent food consumption levels and obesity. On the side of data on obesity, it is to be noted that Italy's come from self-reporting, a method which is generally considered to underestimate the true incidence of the phenomenon ${ }^{15}$. On the side of the data on apparent food consumption, those of the FBS are certainly overestimates of actual intakes because they are inclusive of post-retail waste, which can be considerable ${ }^{4}$. They also contain the errors made in recording production, imports, exports, estimates of

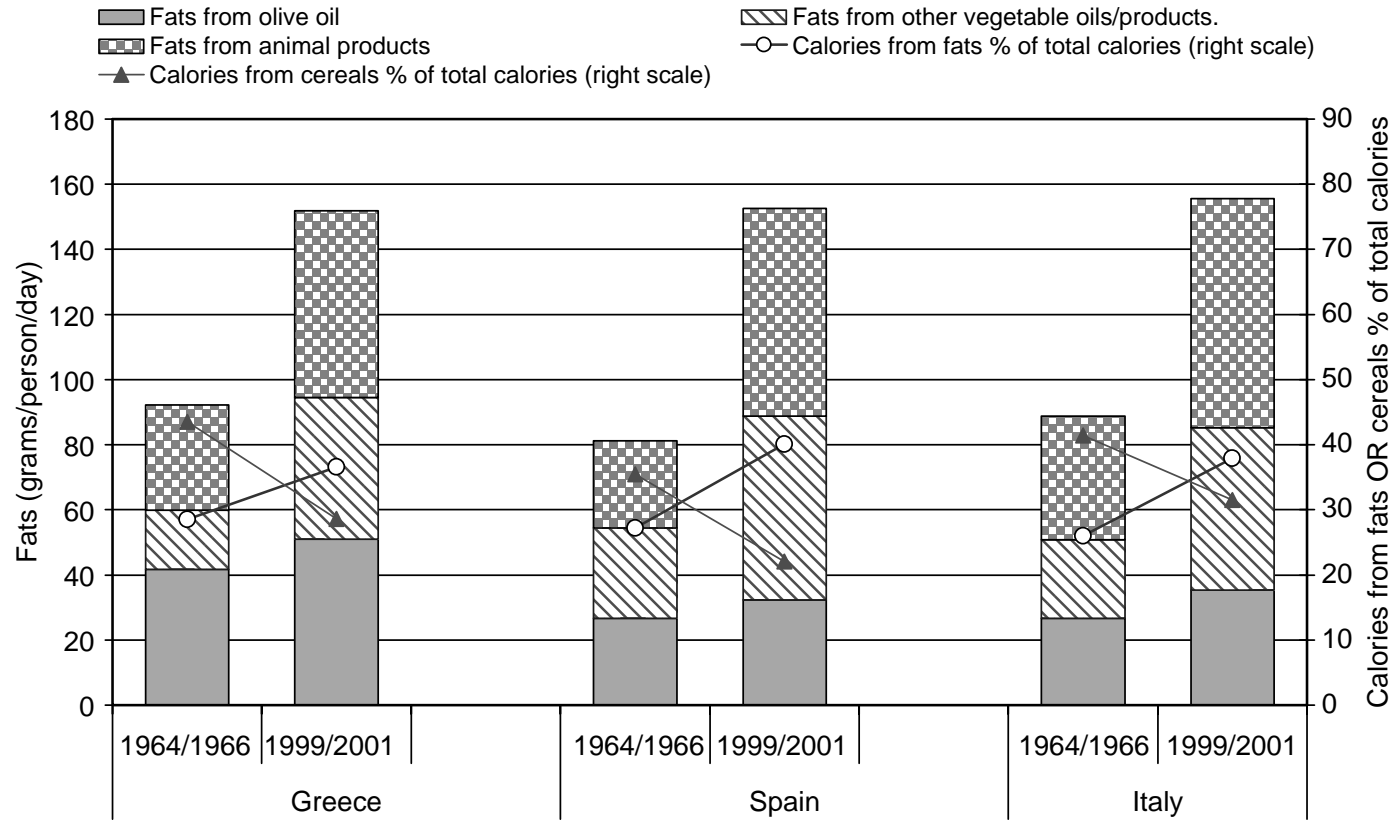

Note. Fats include added fats as well as those embodied in other food products

Fig. 1 Greece, Spain, Italy: diet transition to increased fat consumption 
non-food uses and pre-retail losses of food commodities, though such errors can result in either over- or underestimation-see discussion in Bruinsma, $2003^{8}$ (pp. 380-1).

We have little option but to continue using these FBS data, notwithstanding their considerable shortcomings, because no other source of food consumption data provides as comprehensive coverage (countries, time periods, commodities) of what people have available to eat. In addition, the need to interface food consumption with agricultural production and trade in any policy analysis requires an internally consistent set of data for all variables concerned. Indirectly, some degree of validation of the FBS data comes from the observed accordance of the trends in per capita food consumption resulting from these data with the trends in obesity measurements for countries which have data on the latter for more than one time period. Some examples are shown in Fig. 2.

It is seen that obesity is shown as having increased in Spain from $7 \%$ in 1987 to $13 \%$ in 2001, a trend that parallels that of the apparent national average food consumption revealed by the FBS. In contrast, data from Spain's Household Budget Surveys of 1980-1981 and 1998-1999 indicate that there has been a fairly generalised decline in per capita food consumption (or availability) ${ }^{16}$, a trend clearly at variance with the data showing growing obesity and growing national food supply from production and imports (net of exports). It would seem that these data consistently underestimate consumption, mainly because they more often than not capture only the part of food purchased for home consumption. Yet, the share of total food consumed away from home (restaurants, workplace cantinas, fast-food outlets, etc.) has been growing by leaps and bounds ${ }^{17}$. By reductio ad absurdum we may note that if per capita consumption of meat had not risen, it would be difficult to explain how Spain's production of meat (mostly pigmeat) grew so fast (by some 80\%) over that period, given that increased net exports of pigmeat and products took only a small part of the total increase in production.

\section{Issues in diet transitions and thinking about policy responses}

A growing number of developing countries are embarking on nutrition transitions. While such progress will improve the welfare of significant parts of the world's population currently in poverty and suffering from inadequate access to food, experience shows that the associated risks of dietrelated NCDs will also be rising. WHO's proposed Global Strategy on Diet, Physical Activity and Health ${ }^{18}$, if adopted and acted upon, holds promise of maximising benefits of such transition and minimising adverse effects. The recommendations concerning increased intakes of fruits and vegetables and substituting monounsaturated fatty acids (plentiful in olive oil, but also in canola oil) for other fats would favour the further adoption of the MD. Countries exporting Mediterranean products would gain some competitive advantage in the world market. Perhaps it is no coincidence that in recent years a good part of the expansion of world consumption of olive oil was accounted for by increases in countries with no or little tradition in olive oil production and consumption, e.g. North America, non-Mediterranean Europe, Japan, Australia and Brazil ${ }^{19}$.

The growing awareness of the high costs imposed on society by the spread of diet-related diseases, both in terms of the health welfare of individuals and the pressures on the national health systems, provide a strong case for policies to promote healthy diets. It also provides

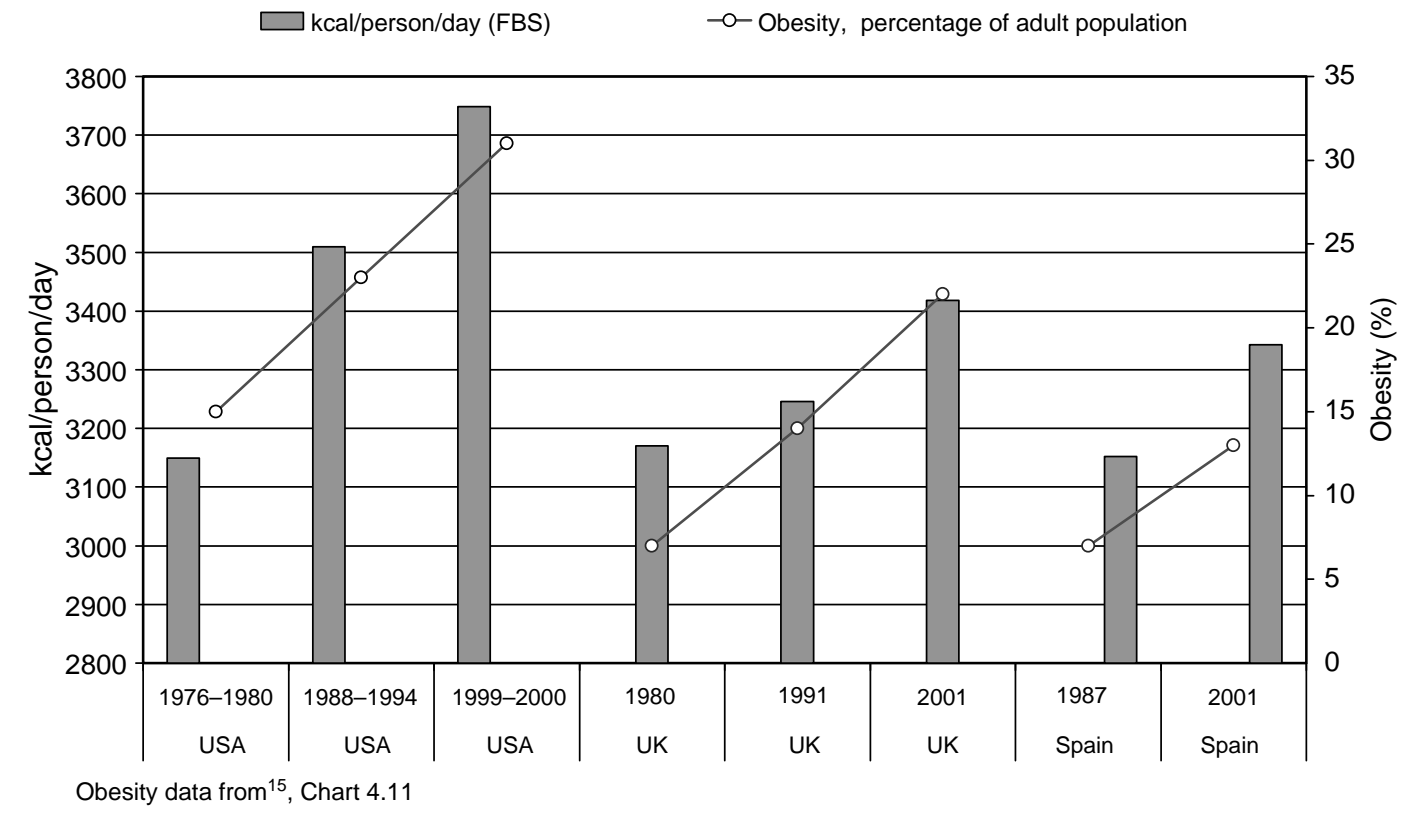

Fig. 2 Changes over time: kcal/person/day and obesity rates 
an additional argument in favour of action now to reduce the incidence of hunger and undernutrition in the many low-income countries facing that problem, given that, according to some, children born to undernourished mothers and/or in populations with long histories of food deprivation face higher than average risks of developing diet-related diseases in adulthood in environments of easier access to food supplies ${ }^{10,20}$. There is less consensus on what are appropriate policy responses-see discussion in Schmidhuber, $2005^{21}$. At the one extreme are views emphasising nutrition education and provision of information on the pros and cons of alternative lifestyles and the attributes of the different food products (e.g. by means of appropriate labelling), but not otherwise interfering with eating choices of individuals. In short, according to this view, it is the responsibility of the informed individual to adopt lifestyles that would reduce the risk of diet-related diseases.

At the other extreme, there are those who consider that it is the responsibility of the state to adopt more interventionist policies that would influence choices in favour of healthier food consumption patterns and lifestyles, e.g. policies akin to those used to discourage smoking. Examples include the banning of advertising of unhealthy foods, particularly to children, or outright restricting access to them (e.g. in schools), or making them more expensive by taxing them (e.g. a tax on fattening foods). In the extreme case, the option is sometimes aired of taxing fat people, e.g. through higher contributions to the health insurance schemes. This is predicated on the notion of the existence of externalities, i.e. that people with 'inappropriate' eating behaviour leading to obesity and associated disease should be made to bear a higher proportion of the costs themselves rather than impose them on others in collectively funded health systemssomething akin to the 'polluter pays principle'.

The policy dilemmas are certainly of no easy resolution, particularly in the light of the evidence that, at least in industrial countries, spreading obesity is increasingly encountered among the poor rather than in the well-to-do classes. In such cases, making fat people (hence predominantly poor) pay more would tend to subvert the very notion of social justice underlying most national health systems. This policy option may, however, have some merit for the developing countries undergoing diet transitions, where overweight and obesity are encountered, at least in the early stages, in the better-off population groups rather than among the poor.

Taxing food items rich in fat may or may not be effective in shifting diets of the population groups tending to overconsume such foods. If they are rich, higher (after tax) prices of these foods will probably have little effect as the rich have low price elasticities of their demand for food. In addition, it may penalise those who need high-energy intakes because of the work they do and who are more likely than not to be poor, e.g. rural workers. If the overweight people are poor, most likely the case in the high-income countries, the effectiveness of such policies would depend, inter alia, on whether they will be able to afford sufficient quantities of at least some of the more expensive healthier foods (fruits, vegetables, fish) to substitute for part of the energy-dense food items that are often cheaper ${ }^{22}$. It may happen that, following the imposition of the tax on 'bad' foods, the prices of the more preferred foods would rise because of the shift of the demand in their favour. In such situations, the poor could easily be priced out of the market of such healthier foods and revert to the consumption of the 'bad' ones. The limiting case is that they may end up changing their diets further in favour of the 'bad' foods. This could happen if the general rise in the food price level following a tax on fat foods were to reduce their overall purchasing power, i.e. make them poorer and reinforce their spending patterns in favour of cheap calories.

There is certainly something to be said for policies that, rather than raise the price of 'bad' foods, actually reduce that of the healthier ones, e.g. through measures to reduce production and, particularly, distribution and marketing costs, or that reduce barriers to imported food. It is likely that aficionados of the MD would abhor any thought of having fresh fruits and vegetables be imported, sometimes from far-away places, just for the sake of having them cheaper. After all, the very notion of promoting the MD is predicated not only on its health merits but also on the benefits it bestows to society at large through the preservation of the culture (with local production being an integral part of it) that gave rise to the MD in the first place. However, we should be aware that such arguments can be, and often are, abused to the point of becoming thinly veiled positions for trade protectionism.

\section{References}

1 Brown L. Tough Choices: Facing the Challenge of Food Scarcity. New York: WW Norton, 1996.

2 Alexandratos N, ed. World Agriculture: Towards 2010, an FAO Study. Chichester/Rome: John Wiley and Sons/FAO, 1995.

3 Alexandratos N. World food and agriculture: outlook for the medium and longer term. Proceedings of the National Academy of Sciences of the USA 1999; 96: 5908-14.

4 Kantor L. A Dietary Assessment of the US Food Supply: Comparing Per Capita Food Consumption with Food Guide Pyramid Serving Recommendations. Agricultural Economics Report No. 772. Washington, DC: US Department of Agriculture, 1998.

5 Food and Agriculture Organization of the United Nations. The State of Food Insecurity in the World. Rome: FAO, 2004.

6 Alexandratos N. Countries with rapid population growth and resource constraints: issues of food, agriculture, and development. Population and Development Review 2005; 31(2): $237-58$.

7 World Health Organization. Diet, Nutrition and the Prevention of Chronic Disease. Report of a Joint WHO/FAO 
Expert Consultation. WHO Technical Report Series 916. Geneva: WHO, 2003.

8 Bruinsma J, ed. World Agriculture: Towards 2015/30, an FAO Perspective. London/Rome: Earthscan/FAO, 2003.

9 Dhillon A. India has no beef with fast-food chains: the country has adapted American fare to satisfy its own tastespicy and vegetarian. Financial Times, 23 March 2002.

10 Schmidhuber J, Shetty P. The nutrition transition to 2030, why developing countries are likely to bear the major burden. Plenary paper presented at the 97th Seminar of the European Association of Agricultural Economists, University of Reading, England, 21-22 April 2005 (http://www.fao.org/ es/esd/gstudies.htm).

11 World Bank. Global Economic Prospects 2006. Washington DC: World Bank, 2005.

12 International Consensus Statement Dietary Fat, the Mediterranean Diet, and Lifelong Good Health 2000, International Conference on the Mediterranean Diet, Royal College of Physicians, London, 13-14 January 2000 (http://europa.eu.int/comm/agriculture/prom/olive/ medinfo/uk_ie/consensus/index.htm).

13 International Obesity Task Force. EU Platform on Diet, Physical Activity and Health-Briefing Paper. Prepared in collaboration with the European Association for the Study of Obesity, Brussels 15 March 2005 (http://www.iotf.org/ media/euobesity3.pdf).

14 Moschandreas J, Kafatos A. Food and nutrient intakes of Greek (Cretan) adults: recent data for food-based dietary guidelines in Greece. British Journal of Nutrition 1999; 81(Suppl. 2): S71-6.
15 Organization for Economic Co-operation and Development. Health at a Glance, OECD Indicators 2003. Paris: OECD, 2003.

16 Data Food Networking-DAFNE (www.nut.uoa.gr).

17 Cutler D, Glaeser E, Shapiro J. Why have Americans Become More Obese? Harvard Institute of Economic Research, Discussion Paper No. 1994, 2003 (http://post.economics. harvard.edu/hier/2003papers/2003list.html).

18 World Health Organization. Process for a WHO Global Strategy on Diet, Physical Activity and Health. Geneva: WHO, 2003.

19 Alexandratos N. Mediterranean countries and world markets: basic foods and Mediterranean products. In: Brauch HG, Liotta HP, Marquina A, Rogers P, Selim EM, eds. Security and the Environment in the MediterraneanConceptualising Security and Environmental Conflicts. Heidelberg: Springer, 2003; 813-26.

20 Food and Agriculture Organization of the United Nations. Fighting Hunger Today Could Help Prevent Obesity Tomorrow. Rome: FAO, 2004 (http://www.fao.org/ newsroom/en/news/2004/36847/index.html).

21 Schmidhuber $\mathrm{J}$. The growing global obesity problem: some policy options to address it. Paper presented at the 97th Seminar of the European Association of Agricultural Economists, University of Reading, England, 21-22 April 2005 (http://www.fao.org/es/esd/gstudies.html).

22 Darmon N, Briend A, Drenowski A. Energy-dense diets are associated with lower diet costs: a community study of French adults. Public Health Nutrition 2004; 7(1): 21-7. 